\title{
Investment Preferences and Risk Level: Behavior of Salaried Individuals
}

\author{
Dr. Taqadus Bashir (Supervisor), Hassan Raza Ahmed (Ms. Scholar) ${ }^{1}$, Sheraz \\ Jahangir (Ms. Scholar) ${ }^{2}$, Samina Zaigham (Ms. Scholar) ${ }^{3}$, Hifza Saeed (Ms. \\ Scholar) ${ }^{4} \&$ Sameera Shafi (Ms. Scholar) ${ }^{5}$ \\ (Business Administration, University of Gujrat, Pakistan)
}

\begin{abstract}
The study aimed to analyze the relationship of demographic variables with the investment preferences consisting of stock investment and gambling decisions of salaried individuals of finance teachers and bankers of Gujrat and Sialkot.The questionnaires were distributed to analyze the significant differences in risk level and investment preferences by taking a sample of 120 individuals. Findings of this research indicated that females are more risk averse than males whereas young and educated people are attracted more towards new risky investment opportunities and want to invest their money but they are reluctant because of limited resources and lack of investment opportunities and absence of investment trends. In addition the emergence of frequent religious issues, non conducive economic environment and culture are found to be the main factors having negative relationship with gambling while making investment decisions.
\end{abstract}

Key Words - demographic factors, gambling, Investment preferences, salaried individuals

\section{Introduction}

Every individual want to invest money in order to get return and for productive use of money. For businessmen it is easier for them to invest in various types of investment assets such as fixed deposits, equity shares, bonds, real assets and saving certificates etc due to number of sources, earnings from their business. As far as Salaried individuals are concerned their investment choices are restricted due to fixed salary package. Investment management (selection of one or other investment assets) varies from businessman and salaried persons. People of different age, education, gender, income and family background are attracted towards different investment activity, the availability of money to invest decides whether investor is potential or not. Investment needs rewards and commitment to the sources in order to earn benefits in future.

Any potential investor invest in shares of a company for return in form of dividend and price appreciation in the market price of his holding .Salaried employees seek return, safety, liquidity, convenience and affordability and tax benefits (B.B.S. Parihar and K.K.Sharma 2012)

Salaried individuals have different preferences of investment decisions according to the demographic variables. This research is concerned with age, gender, education and income of the salaried person and measurement of risk level of individuals and their investment preferences. This research is concerned with investment of salaried individuals in equity shares and whether are attracted towards gambling or not. Risk tolerance is concerned with degree of uncertainty that investor can tolerate in case of negative change in value of his or her portfolio, Investor tolerance of risk is affected by individual characteristics such as age, income, qualification, family background, investment knowledge and attitude towards price fluctuations ,These demographic factors provides as starting point in identification of risk tolerance, it is the complex process that is started form the demographic factors More research is needed to determine which additional factors, such as expectations, attitudes, preferences, family background and culture, and financial stability factors, can be used by investment managers to increase the explained variance in risk-tolerance differences.( Eugin Demiral, 2011). Cognitive theory explains the most comprehensive model of lottery gambling. The cognitive theory of gambling emphasizes the gamblers' irrational beliefs at the different stages of their activities (Griffiths and Wood 2001; Rogers 1998)

\section{Significance Of The Study}

The research is exploratory and conducted in Gujrat and Sialkot. Both cities are in the initial stages of their development with absence of investment trends and lack of opportunities to invest in stock. People possess knowledge but far away from its practical implications, even people who are giving financial knowledge to students are limited to the bookish rates and definitions, and bankers who deal with interest rates, time value of money show repulsive behavior towards investment in shares and gambling. The research investigated these differences in behaviors in quantitative terms that will help the readers to modify their behaviors and practical 
implication of the financial information which they possess. This research is a step towards financial awareness and development of these cities and explores the field of behavior finance.

\section{Contribution To Existing Literature}

As research analysis and results salaried people have knowledge and income and they want to invest in stocks but they don't invest. They find gambling is interesting but they don't gamble. The factors involve to stop them are environment, culture and religious factor. The main contribution is to expand the area of behavioral research. This is the very first study on the behavior of salaried individuals of Gujrat and Sialkot for stocks investments. This research explores the concept of behavior finance and investments in stocks and preferences for gambling in these cities.

\section{Objective Of Reserch}

The respondents for this research are selected from Gujrat and Sialkot two industrial cities of Pakistan. Being industrial cities, the employees of industries have knowledge but lack of investment opportunities in comparison with other cities of Pakistan. The objectives for conducting this research are as follow:

I. To analyze the risk level of salaried individuals according to their income, education and age.

II. To analyze risk differential between salaried males and females.

III. To identify_the preferences of salaried individuals in stocks and gambling.

\section{Literature Review}

Geetha and Ramesh (2011) conducted a research in India on people's behavior about investment preferences. There were lot of options for investment like equity, mutual bonds, company funds, gold/silver, bank deposits, real estate and life insurance etc. But people prefer them according to their choices which were most appropriate and suitable for them. This studies show that how people plan to their investment to meet their objectives and goals. Questionnaire was used to conduct the research and the sample size of this study is 210 . They check people preferences according to their age, income, education, savings and gender. This study find that the people were not properly aware to the investment options, they have lack of knowledge about risky and less risky securities.

The other study conducted in Coimbatore District by R. Sreepriya and P. Gurusamy (2013). They conducted research on subject investment pattern of salaried persons. According to this research paper salaried persons always invest to secure their money for making useable for their future to meet various expenses. They preferred increments on their investments but they were possessive about their investments rather than high returns or gains on investments. These preferences vary to another because every individual don't maintain equal level of investments, savings, needs and returns. The sample size of this study is 150 and data was collected by using primary ways like questionnaire and surveys. The secondary data collected by using internet, journals and research articles. The investment securities are equity, municipal bonds, corporate bonds, real estate, gold post offices and bank deposits. They measure investment level according to educational qualification.

The research study of Elisa C., Gloria G. and Ugo Rigoni (2012) was experimental, which conducted by the help of Laboratory of Experimental Economics of Ca' Foscari University of Venice. This research paper focused on financial education of individuals to getting proper knows how about investment in securities and measuring their risk level. Proper education is necessary for individuals to make diversify investments. Individuals who don't have high income depend on their investments so they are required to allocate their assets properly for diversified portfolio. 200 questionnaires were used for collected data of research study. The results of this research study clearly describe that financial literacy had positive relationship with risk level of individual persons. It's also described that proper education cause's low risk securities investment. This study recommends that government should started financial education programs to give proper awareness to the individuals for investment.

The research study on risk level, age, job level and education of individuals conducted in Bahrain by Jasim Y. A. (2011). This study investigated that wealthier and properly educated people are more risk seeker as compare to others who are less wealthy and less educated. It state that at the early age or in youth people like to seek more risk and when the age grow up and reach to retirement age they become less risky. The residents of Bahrain are less risk tolerance as compare to non Bahrain people. The gender difference risk tolerance research also made in this research paper. The findings and results of research justify their hypothesis that education is necessary to invest in securities like stock, bonds, debentures etc. the people are not aware of level of risk and not aware to nature of securities were not willing to invest or more risk averse.

It's the Indian research conducted in Orissa. In this study Giridhari M. and Dr. Sathya S. D. (2011) analyzed the investment preferences of individuals. They discuss that people were irrational in their decision 
making about investment in securities. The make cognitively or emotionally mistakes in decision making. It happens due to various biases which are being discussed properly in the field of behavioral finance. It explains that investment decisions and risk tolerance of investors depend on age, sex, income, marital status, education, family background, occupation and also the environment on which people lived. The investors of urban areas were targeted for thisresearch study. This research study also cleared that male investors are more risk seeker and more active as compare to female investors. The types of investors are also discussed in this study. Structured Questionnaire and statements used for conducting this research and sample is 210 . The results of study show that individuals invest to full fill their needs and also taking other benefits like safety, tax benefits, high capital gains, liquidity, secured future and for future needs.

This research conducted in India by B.B.S. Parihar and K.K.Sharma (2012) on salaried persons investment preferences. In this paper it is discussed that today investment decisions have become more complicated and difficult. There are the best options for salaried persons that they invest in different investment options according to their preferences as low or high risk to keep their savings in capital gains. This study analyze the impact of different demographic variables like age, gender, income education on the investment decisions of salaried persons. Instead of it other factors like safety, liquidity, return, convenience and tax benefits are material for investment decisions. For this study sample of 200 different demographic characteristics of salaried persons are selected in Agra. The data is collected through questionnaire. The findings of the study described that salaried persons are prefer the secured investments because of fear of losses on small income. Demographic factors were influenced on the investment decisions.

The other study in the field of behavioral finance was conducted on clients of Small Credit Cooperative Bank by Enrico M. C., Pino F. and Pierpaolo P. (2005-2007). This research completed on three years to analyze the affect of age, gender, income, job position and job status on investment decisions. In this research pairs were made of clients for research such as men vs. women, self-employed vs. employee, retiree or housewife, online vs. traditional trader, higher vs. low income (Enrico M. C., Pino F. \& Pierpaolo P. 2005-2007). They data of clients for research were getting from banks. The findings of this research cleared that these variables affect the investment preferences.

According to a study held in Switzerland in 2008, Weing Mei., Keller Carmen and Siegrist Michal. (2008) said that less education you have, the more you will be afraid, This paper surveyed on risk perception of many investment products in German speaking area of Switzerland, They used questionnaire to the respondents which included twenty investment products and ask respondents to rate them on seven scales, According to their findings, knowledge related scales are positively correlated with risk related scales. They said that they traditional finance doesn't deal with biases, they said by taking heterogeneous preferences and beliefs as well as their biases can lead to improve asset pricing model.

This research was conducted in Rajasthan by Dr. Dhiraj J. and Mr. Nikhil M. (2012). They investigated the investment decisions of individuals with demographic variables (age, gender, income, qualification, occupation and marital status). . They used chi square test and correlation for data analysis and the sample size of the study was 200 respondents. They find negative correlation with them. But there was positive correlation between knowledge, income level of investors of different cities. There was no significant relationship between gender on investment decisions in this study.

This study of Shikha B. and Rahul S. in Selected Cities of Rajasthan State. The purpose of their research study was to analyze the influence of factors on investment decision making. The sample cities of Rajasthan State was Udaipur, Jodhpur, Ajmer was Baswara. They used questionnaire of two subscales for collecting data. They used SPSS 15.0 for calculating regression on data. They find out that factors that affect of difference in perception of investor decision on the basis of age, gender, occupation and income group.

This research paper of USA written by Inga C., Michael A. and Barry T. (2008). In it some behavioral biases were discussed. Individuals were prevented by many cognitive and emotional biases during investment decision making which were harmful for assets or investments of individuals. The sample of this study is students of business or behavior finance. They investigated the cognitive biases on them and told that how much education is important to take right decision or to solve these biases. This research paper enhances the need of education because without it investments become sour and causes material losses.

Terrence A. Hallahana, Robert W. Faff and Michael D. McKenzie (2004), investigated the relationship between gender, age, income, education, marital status, number of dependents and net assets with risk tolerance of individuals. They used liner regression for find out the relation between demographic variables and financial risk tolerance. The findings of their research were age and marital status had negative relation with risk tolerance.

This research study of Robert J. Shiller (1998), discussed some theories like regret theory, prospect theory, and cognitive dissonance over confidence, over and under reaction and on gambling behavior or speculations. There are many other biases and anomalies are discussed. In this research it is mentioned that the ratio of gambling and speculations according to the environment and culture of individuals. This was the 
research of USA so their culture encourages the gambling. Gambling decisions and speculation causes increase in unnecessary risk on investments. This research also find out that emotional people were very much involved in gambling.

Ariyabuddhiphongs V., (2010) investigated on lottery gambling. In this research the gambling like playing cards, lotto, lottery and scratch cards are discussed. They discussed that why people were buying lottery. Some buy it as for passion some buy to earn on taking risk. Majority youth are buying lottery tickets. It was started from earlier times that people want to earn more or win large amounts on lottery tickets. They buy it to earn more and quickly but sometimes these tickets ruin the persons by uncertain risks.

There another article was discussed about gambling behavior, financial management and risk management of individual investors. In this article Effie Z.C., Nickii A.D. and Keong Y., (2012) analyzed money attitude discussed about males and females. The sample size of this research was 118. In this sample of research the females were more than the male's participants. The findings of this research stated that gambling behavior was not significantly repeated with financial money and financial attitudes. Demographic factors influence the gambling behavior.

Juuso L., (2010) research about demographic variables such as sex, age, income, education and marital status with the behavior of the investors. How they change and how much investors follow the advice about investments from their advisor and banks. In this research the trading activities of investors were analyzed for a specific time. The research conducted by filling the questionnaire which checks the investor risk level according to their demographic variables. The sample selected for research study is 910 Finnish banks customers. The findings of the research told that some customers don't follow the advices of their banks and some followed. This research also explained the reasons of this behavior. Their behavior was affected by their demographic variables.

There another research on gambling Attitudes, religious beliefs and financial market outcomes conducted by Alok K., Jeremy P. and Oliver S. (2010). In this research they described that gambling attitude according to the religions. It gives the propensity to grow. Religious induced gambling preferences influence people portfolio decision on institutional investors. It's the foreign research where people often buy stocks and hold lottery tickets. The demographic variables also included in this research. It analysis that in a portfolio what is the weight of stock options IPO, lottery type and non lottery type stocks and then check their returns. This research find it that every investor want to invest according to its demographic variables in stock or gambling. The religions also affect this decision because people follow their religious preferences to make such decisions.

\section{Demographic Factors (Independent Variables):}

The relationship of following demographic factors with risk level and investment purpose is analyzed and for the research and these is also considered as independent variables. 6.1 Age

Age of salaried individual also affects its investment preferences. Age is found most important determinant in investor style and young investors are less risk averse then old investors (Lewellen et al. 1977). In a study taken in Missouri University in 2012 Rui Yoa said "Age has a very significant relationship with risk tolerance," "As life span is increased by one year it represents less time horizon for toleration market losses. In addition, Individuals with increasing age go for asset accumulation to asset preservation. They become concerned about potential loss of money when they are near to their retirement.

Thus first hypothesis of this research for risk level is

H1- Young people are more risk taker as compare to old people.

\subsection{Gender}

Many researches are conducted to analyze the gender differences in the risk taking level. According to a study held in Australia in 2009 women and men have different attitudes towards risk level and their investment preferences also differ due to their built in propensity. This research took into consideration how intense are these differences. In the United States, Bruce and Johnson (1994) find that women want to invest in less risky investments because they are risk averse.

Thus second hypothesis for risk level is

$\mathrm{H} 2$-Females are more risk aversers as compared to males

\subsection{Education}

Education also plays a very important role in risk taking level and investment preferences of salaried individual. This leads to the quantity and quality of information an individual holds aside from academic education. The study of Mei Wang in 2008 "Less you know more you afraid of also signifies that less information leads to risk averse behavior." Jasim Y. Al-A. (2011), Christiansen et al. (2006) find that investors who have higher education are more willing to invest in stocks and bonds. Mankiw and Zeldes (1991), Haliassos 
and Bertaut (1995) and Guiso et al (2003) investigate that "More well-educated individuals are more likely to be financial investors".

H3- education has direct relation with risk taking level

\subsection{Income}

Income acts as source for the investment of salaried individuals. High income leads to the incentive for the investment .Individuals with low salary often restricted for investment purposes. Jasim Y. Al-A. (2011) examined that income is the final factor for investment.

H4-High income has direct relationship with risk taking levels.

\section{Dependent Variables}

This research considered following variables as dependent which are explained in the introduction section are:

$\begin{aligned} \text { I. } & \text { Risk Level } \\ \text { II. } & \text { Investment in Stock } \\ \text { III. } & \text { Gambling }\end{aligned}$

VIII. Research Methodology

This research is related to analyses of demographic variables of salaried individuals on their risk level and investment preferences i.e. stock or gambling. The instrument of this research is questionnaires developed by Lennar Sjoberg and Elisabeth Engelbergare distributed among bankers and finance teachers of Gujrat and Sialkot. The main purpose to select these sectors is that they possess relevant information and proper understating of the information being asked. The secondary source internet, journal and articles are used to collect data.

150 questionnaires were distributed and 120 were returned and these responses were coded and analyzed.

To test reliability of instrument and questionnaire of this research, Chronbach's Alpha coefficient of gambling, stock investment and risk level is calculated.

\section{TABLE 1: RELIABILITY STATISTICS FOR QUESTIONS OF STOCK INVESTMENT}

\begin{tabular}{|c|c|}
\hline Cronbach's Alpha & No of Items \\
\hline .558 & 2 \\
\hline
\end{tabular}

The questions for this research about stock investment are 55.8\% reliable according to Chronbach Alpha measurement.

TABLE 2: RELIABILITY STATISTICS FOR QUESTIONS ABOUT GAMBLING

\begin{tabular}{|c|c|}
\hline Cronbach's Alpha & N of Items \\
\hline .862 & 4 \\
\hline
\end{tabular}

The Table 2 shows the reliability by using Chronbach's Alpha of gambling questions. The reliability of gambling questions of this research is $86.2 \%$.

TABLE 3: RELIABILITY STATISTICS FOR QUESTIONS ABOUT RISK LEVEL

\begin{tabular}{|c|c|}
\hline Cronbach's Alpha & N of Items \\
\hline .307 & 9 \\
\hline
\end{tabular}

The third table shows the Chronbach's Alpha reliability about risk level questions. The reliability of these questions is $30.7 \%$ because it's based on the perception of salaried individuals. 


\section{Research Analysis}

The statistical tools used for this research is frequency tables and correlation coefficient on data conducted by questionnaire. The software SPSS 18 used for coding data and for finding the results.

TABLE 4: SEX OF THE SALARIED INDIVIDUALS (BANKERS AND FINANCE TEACHERS)

\begin{tabular}{|c|c|c|c|}
\hline Gender & Frequency & Percent & Valid Percent \\
\hline Male & 80 & 66.7 & 66.7 \\
Female & 40 & 33.3 & 33.3 \\
Total & $\mathbf{1 2 0}$ & $\mathbf{1 0 0 . 0}$ & $\mathbf{1 0 0 . 0}$ \\
\hline
\end{tabular}

The table 4 describes that total respondents are 120 which include $66.7 \%$ male individuals and rest $33.3 \%$ are females. The reasons of low participants of female is that in Gujrat and Sialkot majority of females are housewives and there is low ratio of working women and those are interested in stock investment.

TABLE 5: AGE OF THE SALARIED INDIVIDUALS (BANKERS AND FINANCE TEACHERS)

\begin{tabular}{|c|c|c|c|}
\hline Age & Frequency & Percent & Valid Percent \\
\hline $20-25$ & 30 & 25.0 & 25.0 \\
$26-30$ & 34 & 28.3 & 28.3 \\
$31-35$ & 13 & 10.8 & 10.8 \\
$35-40$ & 28 & 23.3 & 23.3 \\
$40-45$ & 9 & 7.5 & 7.5 \\
Greater then 45 & 6 & 5.0 & 5.0 \\
Total & $\mathbf{1 2 0}$ & $\mathbf{1 0 0 . 0}$ & $\mathbf{1 0 0 . 0}$ \\
\hline
\end{tabular}

The table 2 described that majority of respondent's age between $20-25$ (25\%) and $26-30$ (28.3\%). The ratio of people who are working above 45 is $5 \%$.

TABLE 6: EDUCATION OF THE SALARIED INDIVIDUALS (BANKERS AND FINANCE TEACHERS)

\begin{tabular}{|c|c|c|c|}
\hline Education & Frequency & Percent & Valid Percent \\
\hline Metric & 4 & 3.3 & 3.3 \\
Inter & 4 & 3.3 & 3.3 \\
Bachelor & 36 & 30.0 & 30.0 \\
Masters & 62 & 51.7 & 51.7 \\
M.Phil & 9 & 7.5 & 7.5 \\
PHD & 5 & 4.2 & 4.2 \\
Total & $\mathbf{1 2 0}$ & $\mathbf{1 0 0 . 0}$ & $\mathbf{1 0 0 . 0}$ \\
\hline
\end{tabular}

The table 6 described that majority of sample of this research is highly qualified and well experienced individuals. The ratio of education is $(51.7 \%)$ and $(30 \%)$ of masters and bachelors respectively. These results show that $81.7 \%$ graduate respondents participated in this research.

TABLE 7: INCOME OF THE SALARIED INDIVIDUALS (BANKERS AND FINANCE TEACHERS)

\begin{tabular}{|c|c|c|c|}
\hline Income & Frequency & Percent & Valid Percent \\
\hline $10000-20000$ & 7 & 5.8 & 5.8 \\
$20000-30000$ & 31 & 25.8 & 25.8 \\
$30000-40000$ & 12 & 10.0 & 10.0 \\
$40000-50000$ & 33 & 27.5 & 27.5
\end{tabular}




\begin{tabular}{|c|c|c|c|}
\hline $50000-60000$ & 11 & 9.2 & 9.2 \\
$60000-70000$ & 9 & 7.5 & 7.5 \\
$70000-80000$ & 4 & 3.3 & 3.3 \\
More then 80000 & 13 & 10.8 & 10.8 \\
Total & $\mathbf{1 2 0}$ & $\mathbf{1 0 0 . 0}$ & $\mathbf{1 0 0 . 0}$ \\
\hline
\end{tabular}

By frequency analysis the Table 7 of income described that earnings of people are average, few earn up to 50,000 monthly. In Pakistan which is a developing country and facing population problem. Gujrat and Sialkot are small cities where majority of families are dependent on one earning person. So this monthly salary is only enough to meet the responsibilities and necessities.

TABLE 8: PERCENTAGE OF RESPONDENTS WHO BUY LOTTERY TICKETS

\begin{tabular}{|l|r|r|r|}
\hline & Frequency & Percent & Valid Percent \\
\hline Strongly disagree & 41 & 34.2 & 34.2 \\
Disagree & 46 & 38.3 & 38.3 \\
Agree & 24 & 20.0 & 20.0 \\
Strongly agree & 9 & 7.5 & 7.5 \\
Total & $\mathbf{1 2 0}$ & $\mathbf{1 0 0 . 0}$ & $\mathbf{1 0 0 . 0}$ \\
\hline
\end{tabular}

This table shows that $72.5 \%$ of our respondents are not at all interested in buying lottery tickets, where as only $28.5 \%$ are interested in this investment, this result indicates that majority of salaried individuals avoid buying these lottery tickets due to lack of awareness.

TABLE 9: PERCENTAGE OF RESPONDENTS WHO PLAY CARDS ABOUT MONEY

\begin{tabular}{|l|r|r|r|}
\hline & Frequency & Percent & \multicolumn{1}{|c|}{ Valid Percent } \\
\hline Strongly disagree & 37 & 30.8 & 30.8 \\
Disagree & 56 & 46.7 & 46.7 \\
Agree & 22 & 18.3 & 18.3 \\
Strongly agree & 5 & 4.2 & 4.2 \\
Total & $\mathbf{1 2 0}$ & $\mathbf{1 0 0 . 0}$ & $\mathbf{1 0 0 . 0}$ \\
\hline
\end{tabular}

This table shows that $77.5 \%$ of our respondents don't play cards and $22.5 \%$ are interested in playing cards, this less ratio also indicated that the tendency towards playing card in salaried individuals is less in comparison with buying lotteries.

TABLE 10: PERCENTAGE OF RESPONDENTS WHO HAVE LOST LOT OF MONEY ON GAMBLING

\begin{tabular}{|l|r|r|r|}
\hline & Frequency & Percent & \multicolumn{1}{c|}{ Valid Percent } \\
\hline Strongly disagree & 44 & 36.7 & 36.7 \\
Disagree & 43 & 35.8 & 35.8 \\
Agree & 24 & 20.0 & 20.0 \\
Strongly agree & 9 & 7.5 & 7.5 \\
Total & $\mathbf{1 2 0}$ & $\mathbf{1 0 0 . 0}$ & $\mathbf{1 0 0 . 0}$ \\
\hline
\end{tabular}

Table 8 and 9 shows salaried individuals prefer buying lotteries, and a low percentage shows respondents are somehow interested in playing cards also, this table shows $27.5 \%$ respondents are not satisfied with their gambling decisions. 
TABLE 11: PERCENTAGE OF RESPONDENTS WHO FIND HARD TO QUIT GAMBLE

\begin{tabular}{|l|r|r|r|}
\hline & Frequency & Percent & \multicolumn{1}{|c|}{ Valid Percent } \\
\hline Strongly disagree & 43 & 35.8 & 35.8 \\
Disagree & 39 & 32.5 & 32.5 \\
Agree & 31 & 25.8 & 25.8 \\
Strongly agree & 7 & 5.8 & 5.8 \\
Total & $\mathbf{1 2 0}$ & $\mathbf{1 0 0 . 0}$ & $\mathbf{1 0 0 . 0}$ \\
\hline
\end{tabular}

This table shows $31.6 \%$ of our respondents feel that they are gambling more than their risk tolerance but they are used to it, which mean respondents cannot stop gambling in spite of having risk in it.

\subsection{Correlation Analysis}

Correlation is a measure to find the statistical positive or negative relationship between variables. For this research correlation is used to measure the relation of independent variables with dependent variables.

TABLE 12: CORRELATION OF INDEPENDENT VARIABLES WITH DEPENDENT VARIABLES

\begin{tabular}{|l|l|l|l|l|l|l|l|}
\hline & Risk Level & $\begin{array}{c}\text { Stock } \\
\text { Investment }\end{array}$ & Gambling & \multicolumn{1}{|c|}{ Sex } & Age & Education & Income \\
\hline Risk Level & 1 & & & & & & \\
\hline $\begin{array}{l}\text { Stock } \\
\text { Investment }\end{array}$ & 0.01581025 & 1 & & & & & \\
\hline Gambling & -0.0438732 & 0.56179739 & 1 & & & & \\
\hline Sex & -0.0060688 & -0.1038979 & 0.060238 & 1 & & & \\
\hline Age & 0.11749604 & 0.21401931 & -0.009304 & -0.08826 & 1 & & \\
\hline Education & -0.3191649 & -0.1621128 & -0.109656 & 0.129446 & 0.010472 & 1 & \\
\hline Income & 0.02907766 & -0.0408746 & -0.027435 & 0.092516 & 0.465285 & 0.3314189 & 1 \\
\hline
\end{tabular}

The Table 8 describes the correlation analysis between variables. As defined above the independent variables are demographic variables (age, sex, income, education) and dependent variables are risk level of salaried persons, investment decisions in stocks and gambling or speculation. Males are more risk taker and interest in gambling as compare to the females. Age has positive but not much affected relationship with risk level and stock investment. Because majority of respondents are young so it's prove true that youth are more risk taker but they are not willing to take risk. Education shows inverse relation with risk level, stock investment and gambling. Income has direct relation with risk level. Means as income increases people are more likely to take risk.

It is hypothesized that young people are more risk taker as compare to old people. It proves wrong against of Bodie et al. (1992); Bodie and Crane (1997); Strong and Taylor (2001); Jasim Y. Al-A. (2011); McInish (1982); Alanko (2009) and Juuso L. (2010) and supported the study of Parihar B.B.S. and Sharma K.K. (2012). The table 2 shows that majority of our respondents are young. Their ages lie between $26-30$ and $20-25$. Few people are working who are above 45 . So this shows that young people are more risk taker. These two variables have direct positive relationship but not much significant because in these cities salaried individuals don't want to take risk for stock investment because of limited salary packages.

It is hypothesized that females are more risk aversers as compared to males. It proves true with supported the previous studies Bruce and Johnson (1994); Jianakoplos and Barnesek (1998); Halek and Eisenhauer (2001); Jasim Y. Al-A (2011); Parihar B.B.S. and Sharma K.K. (2012); Haarala (2008); Alanko (2009); Kaustia and Halko (2009) and Juuso L. (2010). The table 1 specified the ratio of age of males and females. Only $33.3 \%$ of females are contributed in this research study. The rest are males. The result of questionnaire specified that females are less risk taker as compare to males. They don't get such opportunities for investment. The other reason is low salary but they are interested to invest in stock. During filling the questionnaire and survey of different banks they give their views that they do job to meet their necessities and responsibilities. They save money only to meet them. They have threat if they invest they loss the money.

The third hypothesis of this research study is education has direct relation with risk taking level.

This research correlation analysis shows the inverse or negative relationship of these two variables. This hypothesis proves wrong against Geetha N. and Dr Ramesh M. (2011), Elisa Cavezzali, Gloria Gardenal and Ugo Rigoni (2012), Guiso and Jappelli (2008), Lusardi, Mitchell (2006, 2008); Lusardi, Mitchell, Curto (2009, 
2010); Van Rooij, Lusardi, Alessi (2007); Lusardi, Tufano (2009). In fact in Table 3 education show that majority of respondents almost $51.7 \%$ have master level qualification. From total of the respondents $81.7 \%$ are graduate that is good point for this research. During survey we also noted the reason when high educated people are not willing to investment. The one of it they are under the fear of losses. They reluctant to invest in stocks or for gambling that they may be lost their money. The other reason of it is Islam. People are not willing to invest or gamble because in Islam it's not allowed.

It's hypothesized that high income has direct relationship with risk taking levels. This hypothesis proves true by supporting previous literature Friedman (1974); Cohn et al. (1975); Riley and Chow (1992); Hallahan et al. (2004); Juuso L. (2010); Parihar B.B.S. and Sharma K.K. (2012); Grable and Lytton (1999). According to the table 7 in which income of the respondents are given. There are average respondents in all categories of income. When income of people increased they are more willing to take risk. But in this research the correlation value is too small because instead of increasing income salaried people don't invested.

\section{Findings}

This study on investment preferences and risk level of salaried individuals has been undertaken with the objective to investigate that how they behave for investment according to their demographic variables. The findings of this research are as follow:

I. The women are risk averse as compare to men. The data for this study collected by finance teachers and from banks. Women are working here but the ratio of them is less than men. The ratios of men are $66.6 \%$ and women are $33.3 \%$.

II. These are under developed cities and people are not aware of risk tolerance profiles and investments in stocks.

III. Gujrat is small city, people have low income, and they hardly bear their family expenses. These individuals have no money to invest.

IV. Sialkot is industrial city but salaried individuals don't invest in stocks or in any other securities because there is absence of trend of investment.

V. Majority of salaried individuals are young. The high ratio is between $20-25$ and $26-30$. But the results show that the relationship is positive but not much significant with risk level and stock investment. Previous literature shows that young people are risk seeker as compare to old but here the situation is quiet different because of lack of awareness of salaried individuals.

VI. The $81.7 \%$ salaried individuals of sample are graduate and out of them $51.7 \%$ have master level qualification. The sample of research selected from finance teachers and banks that have knowledge of finance field but they are not willing to take risk to invest in stocks or to gamble because it is against Islam.

VII. Salaried individuals of banks and finance teachers describe their notion that in Gujrat there is no awareness about investment. There is only bookish knowledge and no practical implication here because of lack of advisers and brokerage houses.

VIII. People preferences for gambling is shown above tables $8,9,10,11$ that only $28.5 \%$ and $22.5 \%$ respondents agree to buy lottery tickets and play card respectively. $27.5 \%$ people lost their money in gambling and $31.6 \%$ individuals find hard to quiet gambling.

\section{Conclusion Of The Research}

The main purpose of this research is to analyze the behavior of salaried individuals of Gujrat and Sialkot about risk level, stock investment and gambling decisions. The situation of these cities is quite different from previous research. All previous literature investigates that higher income or wealthier persons are most willing to invest but in Gujrat and Sialkot salaried individuals do not invest. Parihar B.B.S. and Sharma K.K. (2012) investigate that salaried individuals want to secure their money. They want less risky investments because they pleased with low gains but never bear the losses of their savings. According to this study results $81.7 \%$ of salaried individuals are well educated and earn well. But they have only learning of these things they practically has not been invested. The reason as discuss above is lack of awareness. E. Cavezzali, G. Gardenal, and U. Rigoni (2012) research on financial education and risk taking behavior of individual investors. They find out that education is necessary but regular financial advices are also necessary for investors because they don't construct their portfolio. For diversified portfolio financial advisor is necessary. With lack of investment opportunities and absences of investment trends in Gujrat and Sialkot there is no concept of financial advisors in these cities.

At the end of the research it is concluded that demographic factors have significant relationship with risk level, stock investment and gambling. All findings are given in tables 1 to 12 . Questionnaire is valid according to Chronbach's Alpha calculation. Reliability analysis is calculated for all variables. But another thing 
is that people have knowledge and income but still they are not willing to invest. The reasons behind it are some factors which influence their decisions. They have fear of losses, reluctance and religious factor. During survey when respondents of high salary are disagree for investment and gambling but interested for gambling and investment by answering last question. The reason is asked for them. They respond that it's against the Islam. Islam doesn't allow this that's why instead of interest they are not willing to do this. In Gujrat people are not much aware form stocks investments. Neither there are brokerage houses nor adviser available to advise or construct the portfolio according to the risk tolerance of salaried individuals.

\section{Recommendation On Research Study}

The objective of this research is to analyze the behavior of salaried individuals for investments. After completion of the research study, the findings and conclusion described the proper scenario. Analyzing the study, following are some recommendation.

I. Salaried individuals want secure investments. They should invest in government securities and government bonds which are less risk securities and good way for salaried individuals to utilize their savings. There are no chances of default of these securities.

II. In Gujrat and Sialkot proper brokerage houses should be constructed for awareness of people.

III. Salaried individuals need to understand their risk tolerance level because everyone selects investments according to their risk tolerance level. Lipe (1998), Yang and Qiu (2005) documented that risk is a factor that shapes individuals' decisions, including financial and Investment decisions.

IV. Government should open proper financial education consultants about investments in securities, stocks and bonds in Gujrat and Sialkot. It gives proper awareness and know how about securities to invest for salaried individuals. As in study of Cavezzali and Rigoni (2012).

V. There is need to find the reasons why females are risk averse. Financial advisers can solve these problems. According to previous literature, Jasim Y. Al-Ajmi (2011), risk is the factor that shapes the individuals financial and investment decisions.

VI. Pakistan is Islamic country and its culture is much different from foreign countries. So they don't leave their moral values and Islamic points. To satisfy them encourage for low risk low return investments.

VII. Jasim Y and Al-Ajmi (2011) recommends that investigate thoroughly what is the relation between age and risk aversion, the knowledge of individuals for capital market and its effect on risk tolerance level needs with understanding of education, number of dependents, marital status, social background, family composition.

\section{Acknowledgment}

It is our pleasure to be indebted to various people, who directly or indirectly contributed in the development of this work and who influenced our thinking, behavior, and acts during the course of study. At first, we would like to thanks the almighty ALLAH and our parents for their moral support.

We express our sincere gratitude to our respected Mam Dr, Taqadus Bashir for providing us an opportunity to undergo the research paper.

This was her support, cooperation, and motivation provided to us during the work for constant inspiration, presence and blessings. She provided her valuable suggestions and precious time in accomplishing our project report.

\section{Refernces}

[1]. M. Weing, C. Keller \& M. Siegrist, The less you know, the more you afraid of- A survey on risk perception of investment products.

[2]. R. SreePriya \& P. Gurusamy., Investment Pattern of Salaried People - A Study in Coimbatore District, International journal of Scientific Research, Volume: 2, No 1, ISSN No 2277 - 8179

[3]. N. Geetha \& Dr. M. Ramesh, A Study on People's Preferences in Investment Behavior, IJEMR - Vol 1 Issue 6 - Online - ISSN $2249-2585$

[4]. C. Elisa, G. Gloria \& U. Rigoni, Risk Taking, Diversification Behavior and Financial Literacy of Individual Investors, Working Paper Series, Working Paper n. 17, ISSN: 2239-2734.

[5]. Y. A. Jasim, Risk Tolerance of Individual Investors in an Emerging Market, Journal of Risk and Diversification, ISSN 1986-4337 Issue 2

[6]. M. Giridhari \& Dr. S. D. Sathya , A Study on Investment Preferences among Urban Investors in Orissa, Prerana - Journal of Management Thoughts and Practices, Volume: 3, Issue: 1, ISSN: 0974-908X

[7]. B.B.S. Parihar \& K.K.. Sharma, An Empirical Study of the Investment Preferences of Salaried Employees, Technofame- A Journal of Multidisciplinary Advance Research, Vol.1 No. 2, 39-48

[8]. M. C. Enrico, F. Pino \& P. Pierpaolo, Individual Investor Behavior: Evidence from the Clients of a Small Credit Cooperative Bank, Working Paper version 2011

[9]. C. Inga, A. Michael \& T. Barry, Behavioral Bias within the Decision Making Process, Journal of Business \& Economics Research, Volume 6, Number 8

[10]. J. S. Robert, Human Behavior and the Efficiency of the Financial System, Cowles Foundation for Research in Economics, Paper No. 1172 
[11]. Z.C. Effie, A.D. Nickii \& Y. Keong, An Examination of Gambling Behavior in relation to Financial Management Behavior, Financial Attitudes \& Money Attitudes, International Journal of Mental Health and Addiction, Volume 10, Issue 2, pp 231-242

[12]. K.. Alok, P. Jeremy \& S. Oliver, Religious Beliefs, Gambling Attitudes, and Financial Market Outcomes

[13]. L. Juuso, Risk Tolerance and Myopic Behavior - Evidence from Finnish Retail Investors, Helsingin Kauppakorkeakoulu

[14]. B. Shikha and S. Rahul, Actors Influencing Investment Decision in Selected Cities of Rajasthan State, Tenth AIMS International Conference on Management

[15]. H. Terrence, W. F. Robert and D. M. Michael, An empirical investigation of personal financial risk tolerance, Financial Services Review 57-78

[16]. Dr. J. Dhiraj and Mr. M. Nikhil, Impact of Demographic Factors on Investment Decision of Investors in Rajasthan, International Refereed Research Journal, Vol. - III, Issue -2(3) 